\title{
FROM SECRETARY'S DESK
}

A few extracts of the main objects for which this prestigeous Institute of yours has been established is for your perusal.

1) To promote the advancement of Science and practice of welding.

2) To promote and organise research in all matters relating to the science and practice of welding and cutting

3) To invite from the members and others communications written or oral concerning and relating to the science and practice of welding and to receive, hear and publish Communications.

4) To enable all persons engaged in welding and allied Industries to meet and to corre spond and to facilitate the exchange of ideas with respect to the Science and practice of welding.

5) To enter into arrangements for providing Members of the Company with advice and assistance on all matters connected with the objects covered by our Memorandum.

Dear Collegues a very pertinant questions comes to our mind and is also for your perusal.

DO YOU THINK that it can be done by a few of us.

DO YOU THINK that we will succeed if all members do not participate in totality.

DO YOU THINK that this is possible for us if every year membership subscription is short collected by over 40 percent.

DO YOU THINK that it 'is possible if we do not encourage a very large participation by Industrial Corporate Members.

DO YOU THINK that we will be able to afford 4 issues of IWJ' where expenses are over 2 Lakhs per year and are expected to increase in the years to come.

DO YOU THINK that we are not a NON. PROFIT making Institute.

It is earnestly requested to one and all of you that.

PLEASE pay your subscriptions faithfully and regularly and somehou avoid to default and increase administrating expenses.

PLEASE encourage, enlighten and enrol a large number of Industrial Corporate Members.

PLEASE project your Products and Services on a very regular basis in our 'TWJ" for the personal and benefit of one and all in the family and help us by way of advertisements.

PLEASE send your querries to us and allow our chairman Technical Committee to deal and publish the same in IWJ for the benefit of all.

PLEASE utilise the readers forum and help us in projecting your problems to one and all.

PLEASE note that we can not afford to remain a member of International Institute of Welding as their subscription is beyond our means but can we not develop our Institute with all. so knowledgeable persons, as members such that the other Institutes look to us for our association with them.

We are confident that better wisdom will prevail and we would not like to see that our Institute is just another Institute.

DO HELP US AND HELP YOURSELF. IN. TURN.

Thank you.

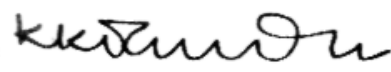

K.K.Tandon

Hony. Secretary 